EESTI NSV TEADUSTE AKADEEMHA TOIMETISED. XI KÖIDE FOOSIKALIS-MATEMAATILISTE JA TEHNILISTE TEADUSTE SEERIA. 1962, NR. 3

ИЗВЕСТИЯ АКАДЕМИИ НАУК ЭСТОНСКОЙ ССР. ТОМ ХІ СЕРИЯ ФИЗИКО-МАТЕМАТИЧЕСКИХ И ТЕХНИЧЕСКИХ НАУК. 1962, № 3

\title{
КРУГЛАЯ И ПЛОСКАЯ ТУРБУЛЕНТНЫЕ СТРУИ, РАЗВИВАЮЩИЕСЯ В СПУТНОМ ПОТОКЕ
}

\author{
Э. ТИММА \\ ю. ИВАНОВ, \\ доктор технических наук
}

Аналитические и экспериментальные исследования закономерностей турбулентных струй, выполненные как у нас, так и за границей, способствовали пониманию физической сущности рабочих процессов, протекающих в различных установках, и позволили для некоторых из них дать количественную оценку явлений переноса тепла и вещества.

Как уже показано в работах $\left[{ }^{8}\right]$ и [9], имеется большое расхождение в определении скорости струи, развивающейся в спутном потоке. Также известно, что экспериментально и аналитически мало изучен переходный участок струи, находящийся между основным и начальным ее участками.

В этой статье сделана попытка экспериментально изучить турбулентную струю, возникающую в спутном потоке, и выяснить некоторые существенные закономерности ее развития. Данная работа является продолжением исследований, проведенных ранее в Институте энергетики АН ЭССР.

Общий вид экспериментальной установки и схема измерений показаны на фиг. 1. Основная часть установки представляет собой горизонтальную аэродинамическую трубу диаметром 700 мм. Воздушный поток в трубе создается вмонтированными в нее двумя аксиальными вентиляторами МЦ-7.

Для исключения вращения основного потока в трубу вставлялись успокоители в виде обичаек с набранными рядами ячеек. Выравнивание скоростного поля потока по сечению трубы производилось тремя рядами сеток. Скорость потока регулировалась на всасывающей части аэродинамической трубы при помощи регулятора секторного типа. В центральной части аэродинамической трубы вдоль ее оси вставлялась изолированная асбестом труба внутренним диаметром 68 мм, соединенная с вентилятором, создающим исследуемую струю. Скорость струи регулировалась на входном патрубке вентилятора. В трубу вмонтирован четырехсекционный регулируемый электрический нагреватель общей мощностью порядка 10 квт. Подача воздуха в трубу из вентилятора осуществлялась через четыре трубки (сплюшенные для уменьшения нарушений основного потока), помешенные симметрично в аэродинамической трубе. Центральная труба, по которой подается струя, оканчивается на срезе аэродинамической трубы съемным соплом на винтовом соединении. В опытах использовались круглые сопла диаметром $d=40$ и 50 мм и плоские сопла шириной $2 b_{0}=14$ мм, длиной $h=200$ мм. 
Измерения динамического напора производились пневмометрической микротрубкой, отсчет показаний которой производился на микроманометре типа ММН с дополнительными уклонами $\sim \frac{1}{16}$ и $\frac{1}{32}$. Измерительные приборы перемещались в потоке с помощью координатника в любую точку измеряемого поля в интервале изменений координат $x$ от 0 до 650 мм и $y, z$ от 0 до \pm 500 мм. Измерения температуры производились двумя термопарами хромель-алюмель сечением из проволоки $\oslash 0,1$ мм с отчетом показаний на переносном потенциометре ПП.

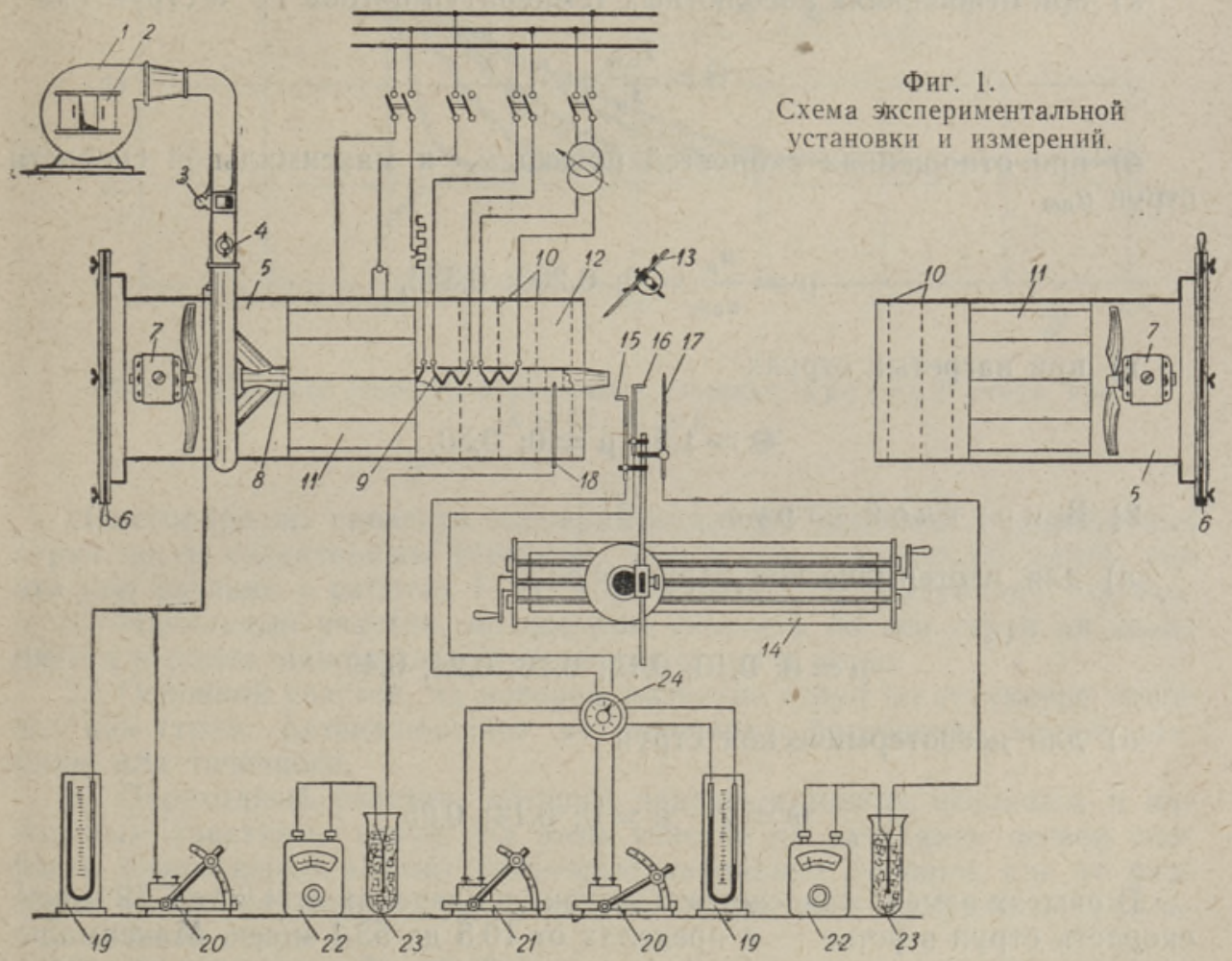

1 - Вентилятор среднего давления; 2 - Шибер на входном патрубке вентилятора; 3,4 - Шибера на выходном патрубке вентилятора; 5 - Аэродинамическая труба для потока $\varnothing 700$ мм; 6 - Регулятор количества засасываемого воздуха основного потока; 7 - Вентилятор МЦ-7; 8 Центральная труба для создания струи - $d_{\text {вн }}=68$ мм; 9 - Нагреватели струи общей мощностью 10 квт: 10 - Сетки для выравнивания скоростного поля потока; 11 - Успокоители в виде обечайки с набранными рядами ячеек для исключения вращения основного потока; 12 - Сетки для выравнивания скоростного поля потока в центральной трубе; 13 - Термометр для нзмерения средней температуры потока; $14-$ Координатник; $15,16-$ Микротрубки для измерения поля скоростей струн; 17 - Термопара с открытым спаем для измерения температурного поля струн; 18 - Режимная термопара для контроля температуры струи в центральной трубе в теченне опыта; 19 - U-образный манометр; 20 - Микроманометр типа MМH; 21 - Микроманометр типа МMH, специально оттарированный с уклонами $\frac{1}{16}$ и $\frac{1}{32}$ для измерения малых значений перепадов давления; 22 - Потенциометр типа ПП; 23 - Сосуды Дьюара; 24 - Переключатель давления. 


\section{Результаты экспериментальных исследований}

Экспериментально изучены начальный и переходный участки. Значительно меньше в данной работе исследовался основной участок турбулентной круглой и плоской струй, развиваюшихся в спутном потоке. В сечениях струи измерены составляющие скорости $u$ по оси $x$ и температура при следующих значениях параметров:

1. В плоской струе

a) при отношениях абсолютных температур потока $T_{\text {н }}$ и струи $T_{\text {от }}$

$$
\Theta=\frac{T_{\mathrm{om}}}{T_{\mathrm{H}}} \approx 1,
$$

б) при отношениях скоростей потока $u_{\text {н }}$ и максимальной скорости струи $u_{\mathrm{om}}$

$$
\mu=\frac{u_{\mathrm{H}}}{u_{\mathrm{om}}}=0 ; 0,200 ; 0,333,
$$

в) при нагретых струях

$$
\Theta \approx 1,5 ; \quad \mu=0 ; 0,30 .
$$

2) В круглой струе

а) для изотермической струи $\Theta \approx 1$

$$
\mu=0 ; 0,10 ; 0,15 ; 0,16 ; 0,24 ; 0,49,
$$

б) для неизотермической струи

$$
\Theta=2 ; \quad \mu=0 ; 0,14 ; 0,25 .
$$

В опытах изменялась скорость потока в пределах от 4,9 до 5,12 м/сек, скорость струи в устье - в пределах от 10,5 до 53,3 м/сек. Максимальная разность температур между ненагретой струей и потоком не превышала $10^{\circ} \mathrm{C}$, и поэтому можно считать, что $\Theta \approx 1$. Температура спутного потока при проведении опытов равнялась комнатной.

Температурное и скоростное поля в сечениях струй оказались достаточно симметричными, и поэтому при определении скоростного и температурного полей имелась возможность проводить измерения в сечениях круглой струи только по горизонтальной линии, проходящей через ее центр.

На фиг. 2 показаны скоростные профили в разных сечениях круглой струи при $\Theta=1$ и $\lambda=4,1$. Мы видим, что в начальном сечении струи скоростной профиль неравномерный и, начиная с расстояния, равного примерно одному диаметру от среза сопла круглой струи, скорость потока на линии сопла не меньше осредненной скорости потока $u_{\mathrm{H}}$. Распределение скоростей по сечению потока почти равномерное. Относительное отклонение от среднего значения скорости $u_{\text {н }}$ не превышает $3 \%$. Заметная деформация скоростного поля, как видно из фиг. 2 , имеется только вблизи сопла. 
Относительная ошибка измерений скорости по ксему объему струи не превышала $3 \%$. Точность измерения была выше у оси струи и падала в. направлении к ее границам. При измерениях температур относительная ошибка не превышала $4 \%$.

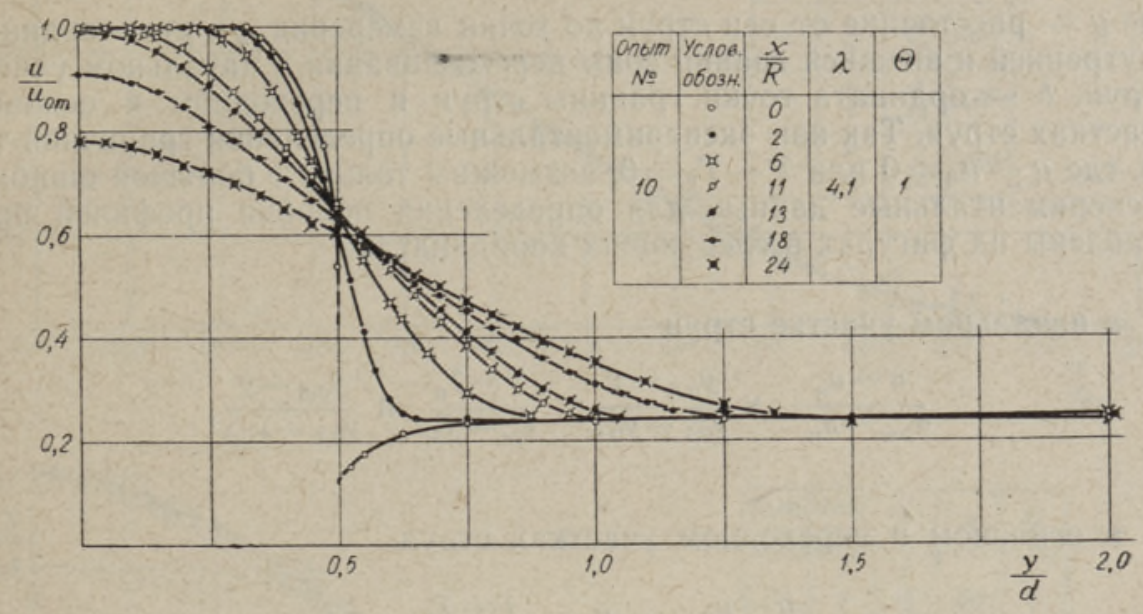

Фиг. 2. Профили скорости в различных сечениях круглой струи, при $\lambda=4,1, \Theta=1$.

Целесообразно провести экспериментальное изучение турбулентной струи по ее характерным участкам. Так, в струе можно выделить, как это уже сделано в работах Г. Н. Абрамовича $\left.{ }^{1-5}\right]$, следующие участки:

1. Начальный участок, на котором скорость по оси струи не изменяется и равна максимальной скорости струи в устье.

2. Основной участок, на котором развитие струи по структуре такое же, как струи, развивающейся из источника бесконечно малой ширины или точечного.

3. Переходный участок, который заключен между основным-и начальным участками струи. На этом участке на за́тухание осевой скорости существенно влияют некоторые начальные условия, как то размеры сопла, начальная турбулизация, скоростной профиль в начальном сечении струи.

Одним из важнейших свойств турбулентной струи является подобие безразмерных избыточных профилей скоростей как в начальном, так в. переходном и в основном участках струи. Здесь под подобием подразу. мевается представление скоростных профилей в разных сечениях струи при помощи одной и той же функции, т. е. действительно следующее соотношение:

$$
\frac{u-u_{\mathrm{H}}}{u_{m}-u_{\mathrm{H}}}=f_{k}(\eta)
$$

где $u, u_{m}, u_{\text {н }}$ - скорости соответственно в произвольной точке струи, по оси струи и в данной точке, $f_{k}(\eta)$ - универсальная функция в сечениях струи, которая может иметь разный вид в начальном, переходном. и основном участках струи, $\eta$ - безразмерная ордината точки, которая в начальном участке струи определяется

$$
\eta=\frac{y-y_{1}}{y_{2}-y_{1}}
$$


а в переходном и основном участках струи

$$
\eta=\frac{y}{\delta}
$$

где $y$ - расстояние от оси струи до точки измерения, $y_{1}, y_{2}-$ ординаты внутренней и внешней границ зоны перемешивания в начальном участке струи, $\delta$ - ордината точки границы струи в переходном и основном участках струи. Так как экспериментальные определения граничной точки, где $u-u_{\mathrm{H}}=0$ или $T-T_{\mathrm{H}}=0$, возможны только с большой ошибкой, экспериментальные данные для определения подобия профилей представлены на фигурах в следующих координатах:

в начальном участке струи

$$
\frac{u-u_{\mathrm{H}}}{u_{\mathrm{o} m}-u_{\mathrm{H}}} \text { н } \frac{y_{0,5}-y}{y_{0,1}-y_{0,9}} ; \quad \frac{T-T_{\mathrm{H}}}{T_{m}-T_{\mathrm{H}}} \text { и } \frac{y_{0,5}-y}{y_{0,1}-y_{0,9}},
$$

в основном и переходном участках струи

$$
\frac{u-u_{\mathrm{H}}}{u_{m}-u_{\mathrm{H}}} \text { и } \frac{y}{y_{0,5}} ; \frac{T-T_{\mathrm{н}}}{T_{m}-T_{\mathrm{H}}} \text { и } \frac{y}{y_{0,5}},
$$

где $y_{0,1}, y_{0,5}$ и $y_{0,9}$ - расстояния от оси струи до точек, в которых безразмерная избыточная скорость $\frac{u-u_{\mathrm{H}}}{u_{m}-u_{\mathrm{H}}}$ равна соответственно 0,$1 ; 0,5$ и 0,9 .

Температурные распределения можно представить еще в координа$\operatorname{Tax}$

$$
\frac{T-T_{\text {н }}}{T_{m}-T_{\text {н }}} \text { и } \frac{y}{y_{0,5}^{\prime}} \text { или } \frac{T-T_{\text {н }}}{T_{m}-T_{\text {н }}} \text { и } \frac{y_{0,5}^{\prime}-y}{y_{0,1}^{\prime}-y_{0,9}^{\prime}},
$$

где $y_{0,1}^{\prime}, y_{0,5}^{\prime}$ и $y_{0,9}^{\prime}$ - расстояния от оси струи до точек, в которых безразмерная избыточная температура $\frac{T-T_{\text {н }}}{T_{m}-T_{\text {н }}}$ равна соответственно 0,$1 ; 0,5$ и 0,9 .

На фиг. 3 и 4 представлены скоростные профили в сечениях турбулентных круглых струй при разных значениях параметров $\Theta$ и $\mu$. Мы видим, что скоростные профили в разных сечениях струи подобны. Это подобие, как видно из фиг. 4б, можно наблюдать в струе примерно от устья $\frac{x}{d}=1$ до конца изучаемой области. Самой подходящей формулой по сравнению с формулами Шлихтинга [111, Сквайра-Троунсера $\left[{ }^{12}\right]$, Толмиена $\left[{ }^{13}\right]$. Гертлера $\left[{ }^{10}\right]$ и др. для определения скоростного профиля является полином

$$
f(\eta)=1-6 \eta^{2}+8 \eta^{3}-3 \eta^{4}
$$

предложенный А. С. Гиневским [7] при определении турбулентного касательного напряжения. Эту формулу для безразмерной скорости можно получить при помощи полиномметода из следующих граничных условий: 

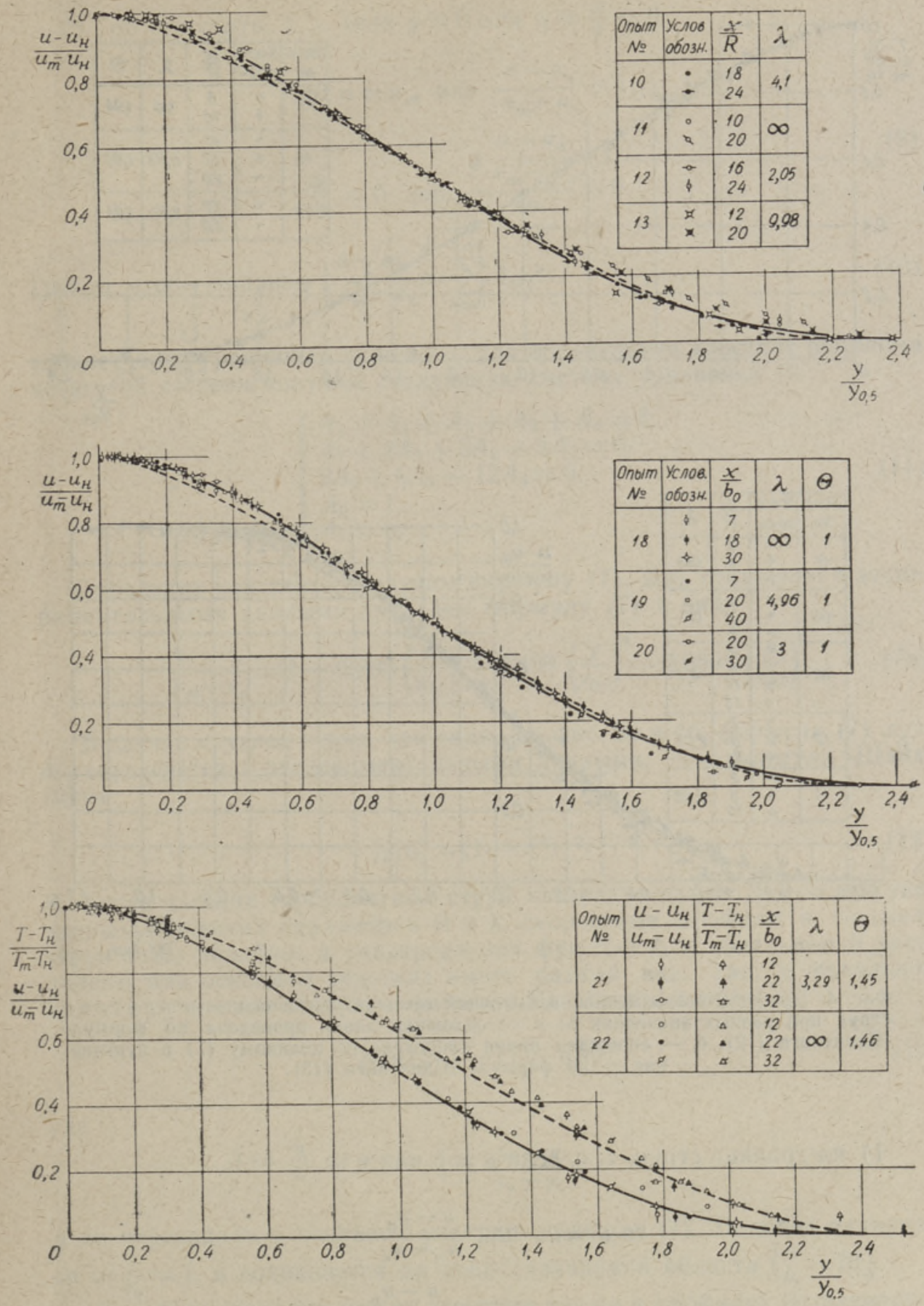

Фиг. 3. Профили безразмерной избыточной скорости и температуры на основных участках круглой и плоской струй при разных значениях $\lambda$ и $\Theta$. Сплошная линия получена по полиному (7). $a-$ круглая струя $(\Theta=1)$, пунктирная линия проведена по формуле Шлихтинга (12); $\sigma-$ п лоск а я струя $(\Theta=1)$, пунктирная линия проведена-по формуле Шлихтинга $(12) ; в-$ плоска я струя $(\Theta=1,5)$, пунктирная линия проведена по формуле (16). 


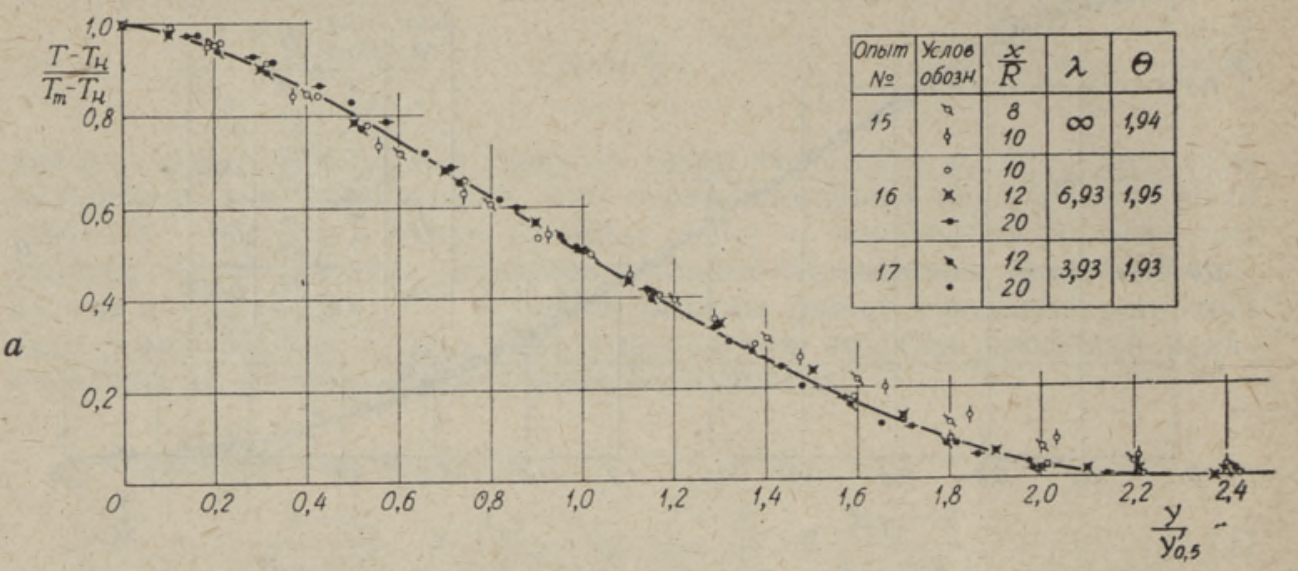

6

\begin{tabular}{|c|c|c|c|}
\hline $\begin{array}{c}\text { Onowm } \\
\text { № }\end{array}$ & 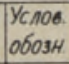 & $\frac{x}{R}$ & $\lambda$ \\
\hline 11 & $\dot{i}$ & $\begin{array}{l}2 \\
6 \\
8\end{array}$ & $\infty$ \\
\hline 14 & : & \begin{tabular}{|l}
2 \\
6 \\
8 \\
\end{tabular} & $\infty$ \\
\hline 10 & $\begin{array}{l}-\infty \\
\hat{\alpha} \\
0\end{array}$ & $\begin{array}{l}2 \\
6 \\
11 \\
13\end{array}$ & $4, f$ \\
\hline 12 & $\begin{array}{l}\text { a } \\
\text { of } \\
\text { a }\end{array}$ & \begin{tabular}{|c}
2 \\
8 \\
12
\end{tabular} & 2,0 \\
\hline 13 & $\begin{array}{l}\Delta \\
\Delta\end{array}$ & $\begin{array}{l}2 \\
6 \\
10\end{array}$ & 9,98 \\
\hline
\end{tabular}

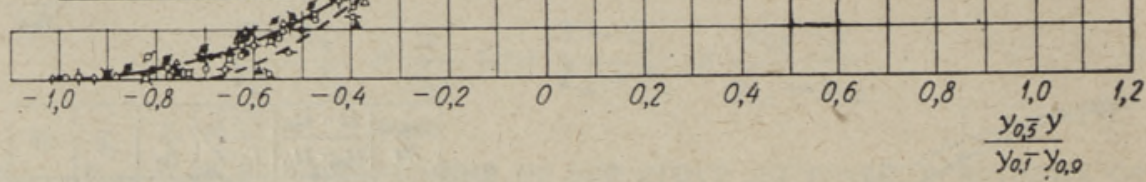

Фиг. 4. Профили безразмерной избыточной температуры и скорости к р угл о й струи при разных значениях $\lambda: a-$ сплошная линия проведена по формуле Шлихтинга (12), б - сплошная линия проведена по полиному (7) и пунктирная - по формуле Шлихтинга (13).

1) на границе струи, т. е. если $y=\delta$ или $\eta=\frac{y}{\delta}=1$,

$$
\begin{gathered}
\text { то } u=u_{\mathrm{H}} \text { или } \frac{u-u_{\mathrm{H}}}{u_{m}-u_{\mathrm{H}}}=0, \\
\frac{\partial u}{\partial y}=0, \text { или } \frac{u-u_{\mathrm{H}}}{\frac{u_{m}-u_{\mathrm{H}}}{d \eta}}=0 \\
\frac{\partial^{2} u}{\partial y^{2}}=0, \text { или } \frac{d^{2} \frac{u-u_{\mathrm{H}}}{u_{m}-u_{\mathrm{H}}}}{d \eta^{2}}=0 ;
\end{gathered}
$$


2) по оси струи, т. е. если $y=0$ или $\eta=\frac{y}{\delta}=0$,

$$
\begin{array}{r}
\text { то } u=u_{m} \text { или } \frac{u-u_{\mathrm{H}}}{u_{m}-u_{\mathrm{H}}}=1, \\
\frac{\partial u}{\partial y}=0 \quad \text { или } \frac{d-u_{\mathrm{H}}}{u_{m}-u_{\mathrm{H}}}=0 .
\end{array}
$$

Требуя, чтобы полином $\frac{u-u_{\mathrm{H}}}{u_{m}-u_{\mathrm{H}}}=\sum_{k=0}^{k=4} A_{k} \eta^{k}$

удовлетворял граничным условиям, для определения констант полинома четвертой степени получнм следующую систему уравнений:

$$
\left\{\begin{array}{l}
A_{0}+A_{1}+A_{2}+A_{3}+A_{4}=0 \\
A_{1}+2 A_{2}+3 A_{3}+4 A_{3}=0 \\
2 A_{2}+6 A_{3}+12 A_{4}=0 \\
A_{0}=1 \\
A_{1}=0
\end{array}\right.
$$

Определив константы, получим формулу (7). Для сравнения с экспериментальными данными приведем формулу (7) к виду

$$
\frac{u-u_{\mathrm{H}}}{u_{m}-u_{\mathrm{H}}}=1-0,893\left(\frac{y}{y_{0,5}}\right)^{2}+0,459\left(\frac{y}{y_{0,5}}\right)^{3}-0,0664\left(\frac{y}{y_{0,5}}\right)^{4} \text {. }
$$

В случае круглой струи, как видно из фиг. $3 a$ и 46, формула (7) лучше согласуется с экспериментальными данными, чем формула Шлихтинга

$$
f_{2}(\eta)=\left(1-\eta^{3 / 2}\right)^{2}
$$

В случае плоских турбулентных струй, как видно из фиг. 36 и 38 , при указанных значениях параметров $\Theta$ и $\lambda$, скоростные профили в сечениях струи тоже подобны, а универсальная функция $f_{k}$ в начальном и переходном или основном участках имеет разный вид. Так, в начальном участке лучше использовать формулу Шлихтинга в виде

$$
f_{3}(\eta)=1-\left(1-\eta^{3 / 2}\right)^{2} \text {, }
$$

где

$$
\eta=\frac{y_{2}-y}{y_{2}-y_{1}}
$$

а на переходном и основном участках полином (7). Подобие начинается от $\frac{y}{b_{0}}=1$ и сохраняется до конца изучаемой области $\left(\frac{y}{b_{0}}=70\right)$.

Указанное подобие можно заметить также в профилях безразмерной избыточной температуры.

Из фиг. 5,6 и $4 a$ видно, что профили безразмерной избыточной температуры в сечениях струи при разных значениях параметров $\Theta$ и $\mu$ подобны в указанных координатах. В переходном и основном участках круглой н плоской струй можно безразмерные избыточные профили определить по формуле Шлихтинга [ ${ }^{11}$; 


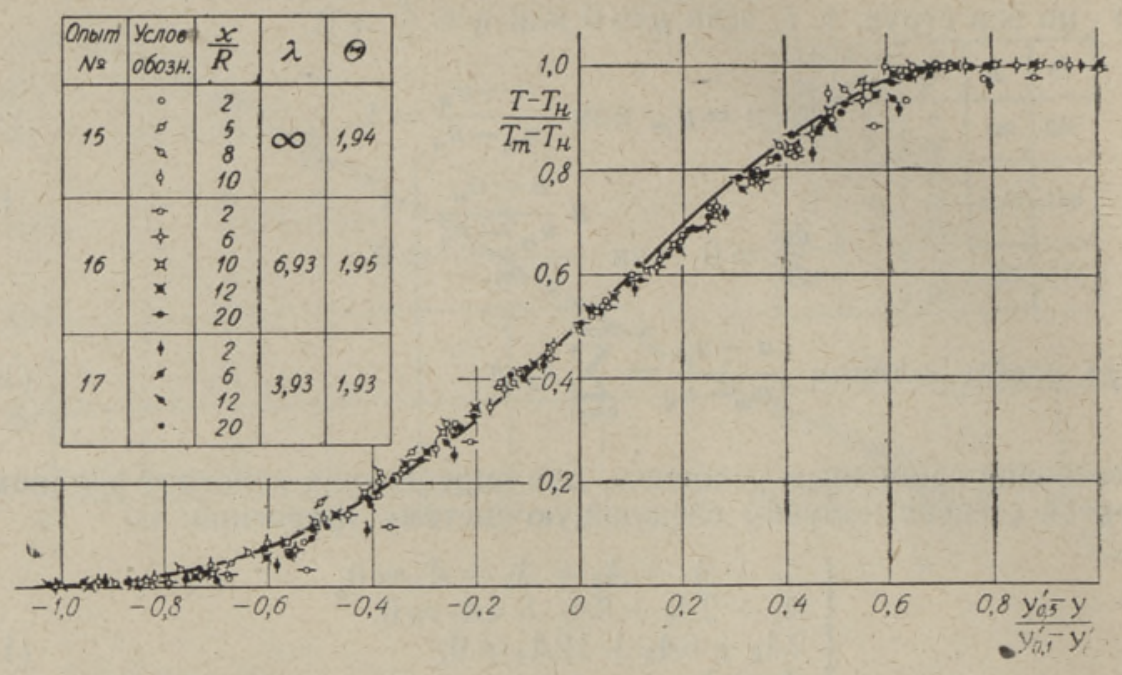

Фиг. 5. Профили безразмерной избыточной температуры неизотермической $(\Theta=2)$ к р углой струи при разных значениях $\lambda$. Сплошная линия проведена по полиному (14).

в начальном участке круглой струи - при помощи полинома

$$
\frac{T-T_{\text {н }}}{T_{m}-T_{\text {н }}}=1-6\left(1-\eta^{\prime}\right)^{2}+8\left(1-\eta^{\prime}\right)^{3}-3\left(1-\eta^{\prime}\right)^{4},
$$

где $\eta^{\prime}=\frac{y_{2}^{\prime}-y}{y_{2}^{\prime}-y_{1}^{\prime}}, y_{2}^{\prime}, y_{1}^{\prime}$ - ордината- граничной точки начального участка, где безразмерная температура $\frac{T-T_{\text {н }}}{T_{m}-T_{\text {н }}}$ соответственно равна нулю и 1 , и в начальном участке плоской струи - по формуле (13).

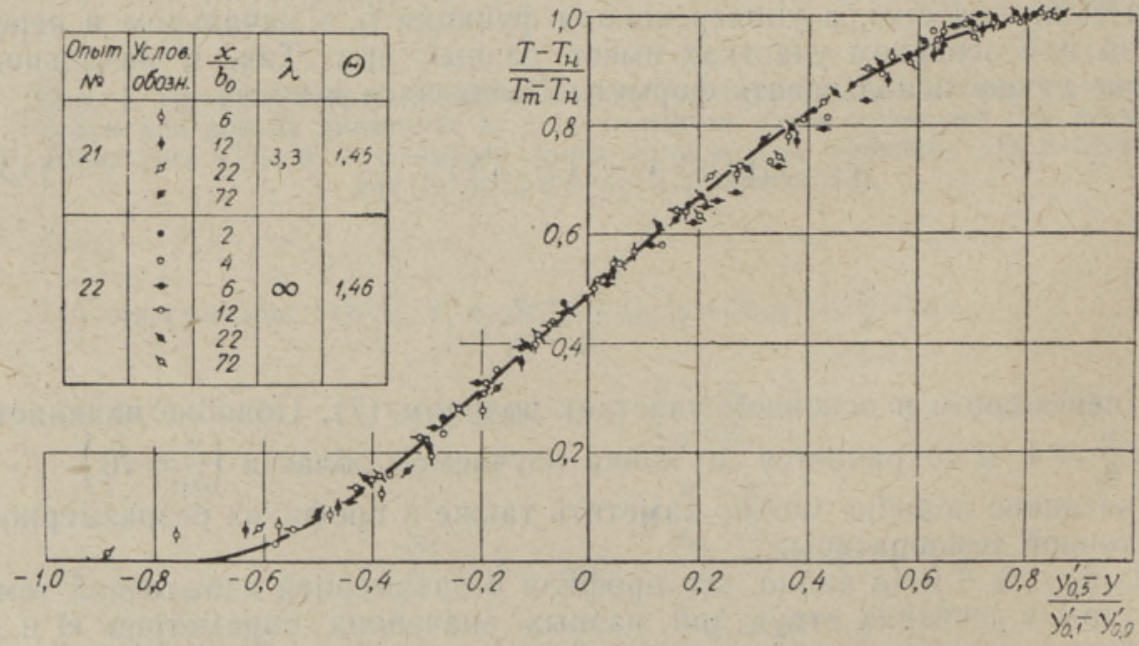

Фиг. 6. Профили безразмерной избыточной температуры в поперечных сечениях неизотермической $(\Theta=1,5)$ п лоской струи воздуха. Сплошная линия получена по формуле Шлихтинга (13). 
Из фиг. $3 в$ видно, что известное соотношение

$$
\frac{T-T_{\mathrm{H}}}{T_{m}-T_{\mathrm{H}}}=\sqrt{\frac{u-u_{\mathrm{H}}}{u_{m}-u_{\mathrm{H}}}}=f_{k}^{0,5},
$$

которое получено на основе теории переноса вихрей Тейлора, не согласуется удовлетворительно с экспериментальными данными, вместо него для плоской струи нужно взять соотношение в следуюшем виде:

$$
\frac{T-T_{\mathrm{H}}}{T_{m}-T_{\mathrm{H}}}=\left(\frac{u-u_{\mathrm{H}}}{u_{m}-u_{\mathrm{H}}}\right)^{0,7},
$$

которое лучше согласуется с экспериментальными данными. Как отмечено в работе Л. А. Вулиса [6], показатель степени 0,7 примерно равняется значению числа Прандтля для воздуха, и это позволяет связать между собой скоростные и температурные поля.

На основании экспериментальных данных определения скорости по оси круглой струи и длины ее начального участка найдена следующая формула

$$
\frac{u_{m}-u_{\mathrm{H}}}{u_{\mathrm{o} m}-u_{\mathrm{H}}}=\frac{1}{\left[\frac{c\left(x-x_{\mathrm{H}}\right)}{R}\right]^{3 / 2}+1}
$$

где $x_{\text {н }}$ - длина начального участка, $R$ - радиуса сопла, $u_{\text {от }}$ - максимальная скорость по оси струи.

В случае изотермической струи, т. е. $\Theta=1$,

$$
\begin{aligned}
\frac{c}{c_{0}} & =\frac{\lambda+21,2}{\lambda+23,8}-0,05 e^{-0,245(\lambda-3,2)^{2}} . \\
\text { и } \frac{c_{0} x_{\mathrm{H}}}{R} & =\frac{19,1}{\lambda^{3}-14,9 \lambda^{2}+84,1 \lambda-70,2}+0,479,
\end{aligned}
$$

где $\lambda=\frac{u_{\text {от }}}{u_{\text {н }}}$ - отношение максимальной скорости струи $u_{\text {от }}$ к скорости потока $u_{\mathrm{o} m}$ и $c_{0}-$ константа, определяемая из эксперимента. Константа c связана с известной константой «a», которая приведена в работе Г. Н. Абрамовича [1]

$$
c_{0}=0,83 \mathrm{a}=0,0547 \text {. }
$$

Для неизотермических струй, если $\Theta=1,94$ и $\lambda=\infty$, то $c=0,0723$ и $\frac{c_{0} x_{\mathrm{н}}}{R}=0,547$, если $\Theta=1,94$ и $\lambda=3,93$, то $c=0,0593$ и $\frac{c_{0} x_{\mathrm{H}}}{R}=0,383$.

На основании обработки экспериментальных данных получена следуюшая формула для определения скорости по оси струи основного и переходного участков

$$
\frac{u_{m}-u_{\mathrm{H}}}{u_{\mathrm{o} m}-u_{\mathrm{H}}}=\frac{1}{\sqrt{c\left(\frac{x}{b_{0}}-k\right)}},
$$

где коэффициенты «с»и «к» имеют следующие значения: 

$\left(u_{\mathrm{H}}>0\right)$

а) в случае изотермической струи $(\Theta=1)$ в спутном потоке

$$
c=0,0946, \kappa=1,43
$$

и в неподвижной среде $\left(u_{\mathrm{H}}=0\right)$

$$
c=0,104, \kappa=1,43 \text {; }
$$

б) в случае неизотермической струи при $\Theta=1,5$

в спутном потоке $c=0,139, \kappa=5,71$

н в неподвижной среде $c=0,156, \kappa=5,71$.
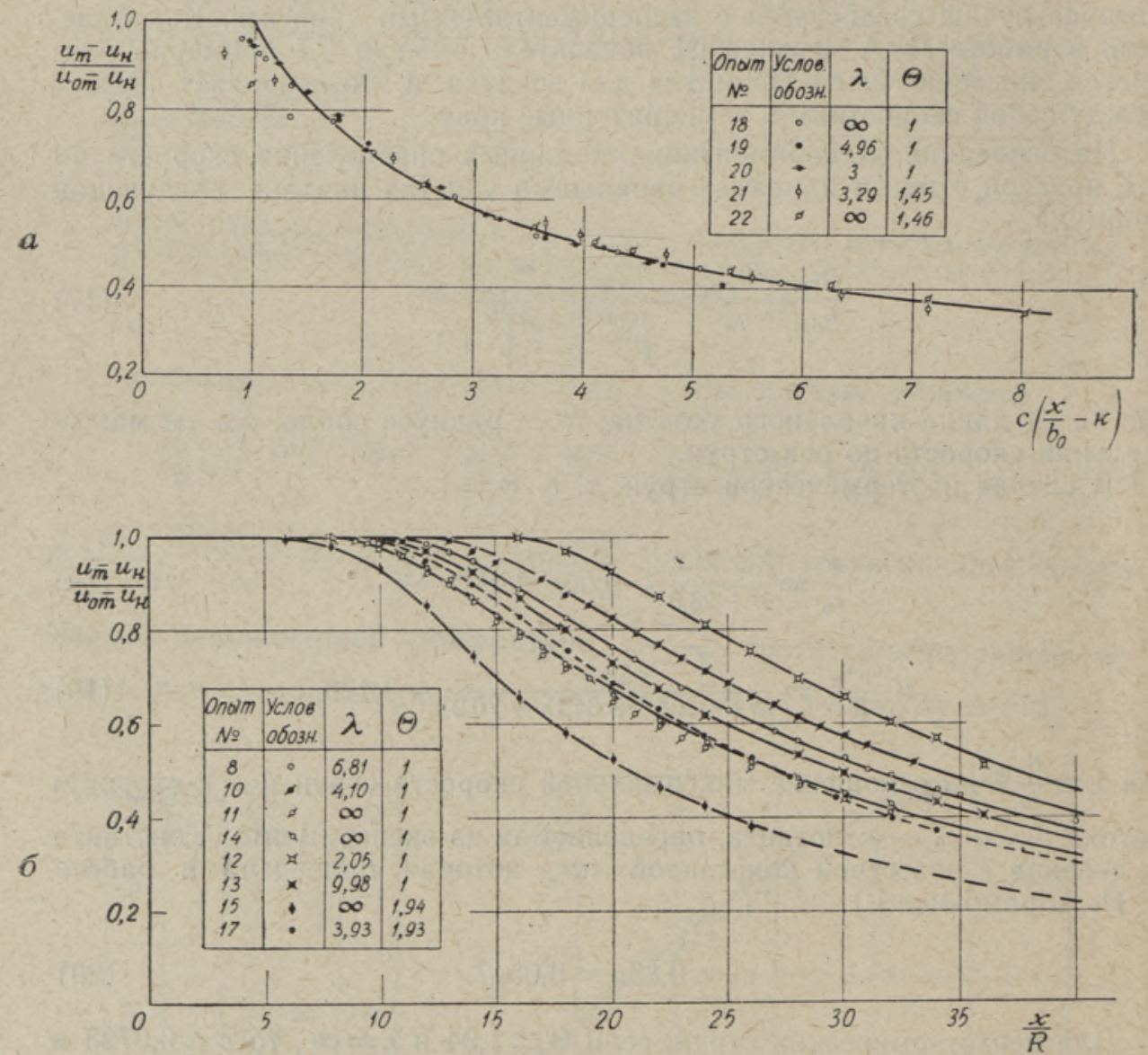

Фиг. 7. Сравнение опытных данных по затуханию безразмерной избыточной осевой скорости струи в спутном потоке с расчетом: $a-$ плоская струя, сплошная линия проведена по формуле $(22)$; 6 - кр углая струя, линии проведены по формуле (17) - сплошные при $\Theta=1$ и пунктирные при $\Theta=2$.

Как видно из фиг. $7 a$ и 7б, эти формулы хорошо согласуются с экспериментальными данными в пределах изучаемой области для плоской струи до $\frac{x}{b_{0}}=60$ и круглой струи до $\frac{x}{R}=40$.

Для плоской струи в области переходного участка, как видно на фнг. $7 a$, расхождение для отдельных точек достигает $5 \%$. 


\section{Выводы}

1. Подобие профилей безразмерной избыточной скорости $\frac{u-u_{\mathrm{H}}}{u_{m}-u_{\mathrm{H}}}$ в разных сечениях струи имеется во всем объеме струи, начиная с расстояния одного диаметра от устья сопла для круглой струи и одной ширины сопла для плоской струи.

2. Подобие профилей безразмерной температуры $\frac{T-T_{\text {н }}}{T_{m}-T_{\text {н }}}$ в разных сечениях струи имеется во всем объеме струи, начиная с расстояния одного диаметра от устья сопла для круглой струи и одной ширины для плоской струи.

3. Самым подходящим выражением для описания профиля безразмерной избыточной скорости в переходном и основном участках круглой и плоской струй является полином (7).

4. Для определения профиля безразмерной избыточной скорости в начальном участке изотермической круглой струи можно использовать полином (7), а для неизотермической круглой струи $(\Theta=2)$ формулу (13).

5. Для определения профиля безразміерной избыточной скорости в начальном участке изотермической и неизотермической $(\Theta=1,5)$ плоских струй можно использовать формулу Шлихтинга (13).

6. Профили безразмерной избыточной температуры можно определить в переходном и основном участках круглой и плоской струй по формуле Шлихтинга (12), в начальном участке круглой струи - по полиному (7), а для плоской струи - по формуле Шлихтинга (13).

7. Связь между профилями безразмерной избыточной температуры и скорости в основном и переходном участках струй можно представить в следующем виде:

$$
\frac{T-T_{\mathrm{H}}}{T_{m}-T_{\mathrm{H}}}=\left(\frac{u-u_{\mathrm{H}}}{u_{m}-u_{\mathrm{H}}}\right)^{n}
$$

где для плоской струи показатель $n=0,7$, а для круглой струи в спутном потоке $n=0,9 \div 1,0$.

8. Для определения скорости по осям круглой изотермической и неизотермической струй (при $\Theta=2$ ), а также длины начального участка изотермической струи предложены формулы (17), (19), которые удовлетворительно описывают все наши экспериментальные данные в пределах изучаемой области $\frac{x}{R}=0 \div 40$ и $\lambda=2 \div \infty$.

9. Для определения скорости по осям изотермической и неизотермической плоских струй (при $\Theta=1,5$ ) основного и переходного участков получена формула (22), которая хорошо согласуется со всеми нашими экспериментальными данными в промежутке $\frac{x}{b_{0}}$ от 10 до 60 м при значениях $\lambda=3 \div \infty$. 
1. Г. Н, Абра мо в и ч, Свободные турбулентные струи жидкостей и газов, Госэнергоиздат, 1948.

2. Г. Н. А бр амович, Турбулентная струя в движущейся среде, Изв. АН СССР, отд. техн. наук, № 6, июнь 1957, стр. 93-101.

3. Г. Н. А 6 ра мови ч, О турбулентном смешении на границе двух плоскопараллельных потоков жидкости (при спутном и встречном движении). Сб. статей № 19 по теоретической гидромеханике под ред. Л. Н. Седова, Оборонгиз, 1956.

4. Г. Н. Аб р а м о и ч, Турбулентная струя в потоке. Тр. совещ. по прикл. газовой динамике, Алма-Ата, 1956.

5. Г. Н. А б р а м о в и, Теория турбулентных струй, Физматгиз, 1960.

6. Л. А. В улис, Струйные задачи прикладной газодинамики, В кн. Исследование физических основ рабочего процесса топок и печей, под редакцией Л. А. Вулиса, Изд. АН Каз. ССР. 1957.

7. А. С. Гин в в ки й, Турбулентный след и струя в спутном потоке при наличии продольного градиента давления, Изв. АН ОТН, Механика и машиностроение, № $2,1959$.

8. Ю. В. И в а но в, Х. Н. С у й, Исследование развития струи в спутном потоке, Изв. АН ЭССР, серия техн, и физ.-мат. наук, т. VII, № 2, 1958.

9. Ю. В. Ив ан ов, Х. Н. С у й, Э. П. Т им м а, Турбулентная изотермическая струя в спутном потоке, Инженерно-физический журнал, т. I, № 5, май, 1958.

10. H. Görtle r, Berechnung von Aufgaben der freien Turbulenz auf Grund eines neuen Näherungsansatzen, Zeitschrift für angewandte Mathematik und Mechanik, 1926, nr. 6, Bd. 6.

11. H. S chlichting, Ueber das ebene Windschattenproblem, Ing.-Arch., Nr. 5, 1930.

12. H. B. Squire and J. Trouncer, Round Jets in a General Stream. Aeronautical Research Committee Reports and Memoranda, No. 1974, January 1944, London (перевод с английского, М., 1947).

13. W. Tollmien, Berechnung turbulenter Ausbreitungsvorgänge, Zeitschrift für angewandte Mathematik und Mechanik, 1926, Nr. 6, Bd. 6.
Институт энергетики
Академии наук Эстонской ССР
Поступила в редакцию
14. XII 1961

\title{
OMAR JA LAPIK TURBULENTNE JUGA PÄRIVOOLUSES
}

\author{
E. Timma \\ J. Ivanov, \\ tehniliste teaduste doktor \\ Resümee
}

Käesolevas töös on eksperimentaalselt uuritud môningaid ümara ja lapiku turbulentse joa arenemise seaduspärasusi liikuvas samasuunalises keskkonnas parameetrite $\lambda=\frac{u_{\mathrm{om}}}{u_{\mathrm{H}}}$ ja $\Theta=\frac{T_{\mathrm{om}}}{T_{\mathrm{H}}}$ erinevate väärtuste puhul, kus $u_{\mathrm{o} m}$ ja $T_{\mathrm{o} m}$ on joa maksimaalne kiirus ja absoluutne temperatuur düüsi suudmes ning $u_{\mathrm{H}}$ ја $T_{\mathrm{H}} \quad$ vastavalt vooluse keskmine kiirus ja absoluutne temperatuur. Eksperimentaalandmetega on vōrreldud mitmete autorite $\left[7,{ }^{10},{ }^{11},{ }^{12},{ }^{13}\right]$ valemeid suhtelise kiiruse ja suhtelise temperatuuri profiilide määramiseks. Ilmneb, et kiiruse ja temperatuuri profiilid joa erinevates ristlốigetes on sarnased ka joa alg- ja üleminekuosas.

Suhtelise (dimensioonivaba) kiiruse ja temperatuuri profiilide ning joa telgkiịruse mää. ramiseks on esitatud vastavad valemid, mis on rahuldavas kooskōlas eksperimentaalandmetega. 


\section{A ROUND AND A SLOT TURBULENT JET IN A CO-STREAM}

\section{E. Timma, Y. Ivanov}

\section{Summary}

The authors present the results of their experimental studies of a round and a slot turbulent jet in a co-stream at different parameters values $\lambda=\frac{u_{\mathrm{o} m}}{u_{\mathrm{H}}}$ and $\Theta=\frac{T_{\mathrm{om}}}{T_{\mathrm{H}}}$ (where $u_{\mathrm{o} m}, T_{\mathrm{om}}$ are the maximum velocity and temperature at the orifice, respectively and $u_{\mathrm{H}}, T_{\mathrm{H}}$ the mean velocity and the mean temperature of the co-stream, respectively).

A comparison of the experimental data with formulae of other authors $\left[7,10,11,12,{ }^{13}\right]$ gives preference to the quoted works.

Experiments have shown that the profiles of the dimensionless velocity excess and the dimensionless temperature excess at various cross-sections are affine, also in the initial region of the jet.

The recommended computation formulae correspond to the experimental data within the whole investigated range.

\section{Academy of Sciences of the Estonian S.S.R.,} Institute of Energetics

Received

Dec. 14th, 1962 